\title{
Significance of Surgery in the Treatment of Colorectal Cancer Ovarian Metastases: A Retrospective Case Matching Study
}

This article was published in the following Dove Press journal: Cancer Management and Research

\author{
Yuqiu Xu* \\ Qingyang Feng* \\ Yijiao Chen* \\ Yihao Mao* \\ Zhiyuan Zhang (D) \\ Yang Lv ID \\ Peng Zheng \\ Shanchao $\mathrm{Yu}$ \\ Guodong $\mathrm{He}$ \\ Jianmin $\mathrm{Xu}$
}

Department of General Surgery,

Zhongshan Hospital, Fudan University,

Shanghai, People's Republic of China

*These authors contributed equally to this work
Correspondence: Jianmin Xu; Guodong He Department of General Surgery, Zhongshan Hospital, Fudan University, 180 Fenglin Road, Shanghai, People's Republic of China Tel +862I-6404-1990

Fax +862I-6403-8038 Email xujmin@aliyun.com; angelhgd@163. com
Purpose: Colorectal cancer (CRC) is one of the most common malignant tumors worldwide. Ovarian metastases (OM), which are low in frequency, are reported to occur in 3-14\% of women with $\mathrm{CRC}$ and have a poor prognosis. Studies have shown that surgical treatment may benefit patients with ovarian metastases arising from CRC. However, the precise benefit of surgery is uncertain. This study was implemented to identify treatment outcomes associated with ovarian metastases from CRC, as well as to clarify the importance of primary and metastatic lesion resection.

Patients and Methods: Between January 2008 and December 2018, the medical records of 93 patients diagnosed with CRC ovarian metastases (CRC-OM) at Zhongshan Hospital, Fudan University, Shanghai, were retrospectively analyzed. Clinicopathological characteristics as well as prognostic conditions were evaluated. Nineteen patients with only synchronous $\mathrm{OM}$ and 38 patients without metastases were matched to compare surgical outcomes. Results: The median overall survival (OS) of the total 93 CRC-OM patients was 26 months. The median OS times of patients with ovary-only metastases $(n=37)$ and those with other metastases $(n=56)$ were 49 months and 20 months, respectively. Patients with only ovarian metastases had a longer OS time $(\mathrm{p}<0.001)$ than patients with other metastases. Patients with ovarian metastases resected $(n=76)(p<0.001)$ had a longer OS time than those unresected $(n=17)$. Synchronous $(n=54)$ and metachronous $(n=39)$ metastases indicated no significant survival difference. Patients with only ovarian metastases could achieve similar OS times to those of patients without metastases after primary and metastasis surgery.

Conclusion: Surgical treatment is very important for CRC-OM patients. Primary and metastatic lesion resection can help achieve longer survival times.

Keywords: colorectal cancer, metastases, ovary, prognosis

\section{Introduction}

Colorectal cancer (CRC) is one of the most common malignancies. The incidence and mortality rates of CRC in China have shown an increasing trend in the past 10 years. $^{1,2}$ CRC has become one of the most common primary sites of ovarian metastases. ${ }^{3}$ Ovarian metastases from $\mathrm{CRC}$, although relatively rare, are a major cause of death among female patients. Grafner et $\mathrm{al}^{4}$ reported that $3-8 \%$ of patients with CRC had visible ovarian metastases, while autopsy showed that $14 \%$ of patients had ovarian metastases.

The number of ovarian metastasis cases has increased with the increasing incidence of CRC. Thus, improving the prognosis of patients with ovarian metastases is 
becoming increasingly urgent. Since the prognosis of ovarian metastases is very poor and since ovarian metastases are not sensitive to chemotherapy, ${ }^{5,6}$ the current study has focused on exploring whether surgical resection of metastases can be an effective treatment for CRC-OM.

Many scholars have been involved in the discussion of the value of surgery; however, the factors that affect the prognosis of patients undergoing surgery are still controversial, and the advantages of surgery have not been well defined or proven. ${ }^{7}$ Moreover, there is no report concerning whether the survival of patients with ovarian metastases can reach the survival level of patients without ovarian metastases.

In this paper, we retrospectively studied the prognosis of patients with CRC-OM and explored the influence of surgery on CRC-OM. We aimed to further clarify the importance of primary and metastatic resection in the treatment of ovarian metastases arising from CRC.

\section{Methods}

\section{Patients}

A total of 93 patients were diagnosed with CRC-OM based on radiological and pathological findings between January 2008 and December 2018 at Zhongshan Hospital, Fudan University, Shanghai. The details of the patients diagnosed by radiography were discussed by members of a multidisciplinary team (MDT), including radiologists, surgeons and gynecologists, to determine their diagnosis of CRC-OM. Synchronous metastases were defined as ovarian metastases detected at the same time as CRC. Metachronous metastases were defined as ovarian metastases detected after the time of CRC. Follow-up information was collected until December 2019. Disease-free survival (DFS) and OS were evaluated from the initial diagnosis of CRC-OM. Clinicopathological characteristics as well as prognostic conditions were retrospectively analyzed. Our study was performed in accordance with the standards of the Ethical Committee of Fudan University Zhongshan Hospital.

\section{Matching}

To compare surgical outcomes between CRC patients with and without ovarian metastases, 19 patients with only synchronous ovarian metastases were used for 1:2 matching. From January 2008 to December 2018, 4635 female patients underwent CRC surgical excision at Zhongshan Hospital. After 763 synchronous metastatic patients were excluded, 3872 patients were available for matching. The following factors were taken into consideration for 1:2 matching: age, preoperative radiotherapy or chemotherapy, primary tumor site, primary tumor size, $\mathrm{T}$ stage, $\mathrm{N}$ stage, primary tumor gross type, primary tumor histology and primary tumor differentiation. In this way, 38 patients were included in the 1:2 matched group (Figure 1).

\section{Statistical Analysis}

Survival was analyzed with the Kaplan-Meier method and was compared using the Log rank test. Variables found to

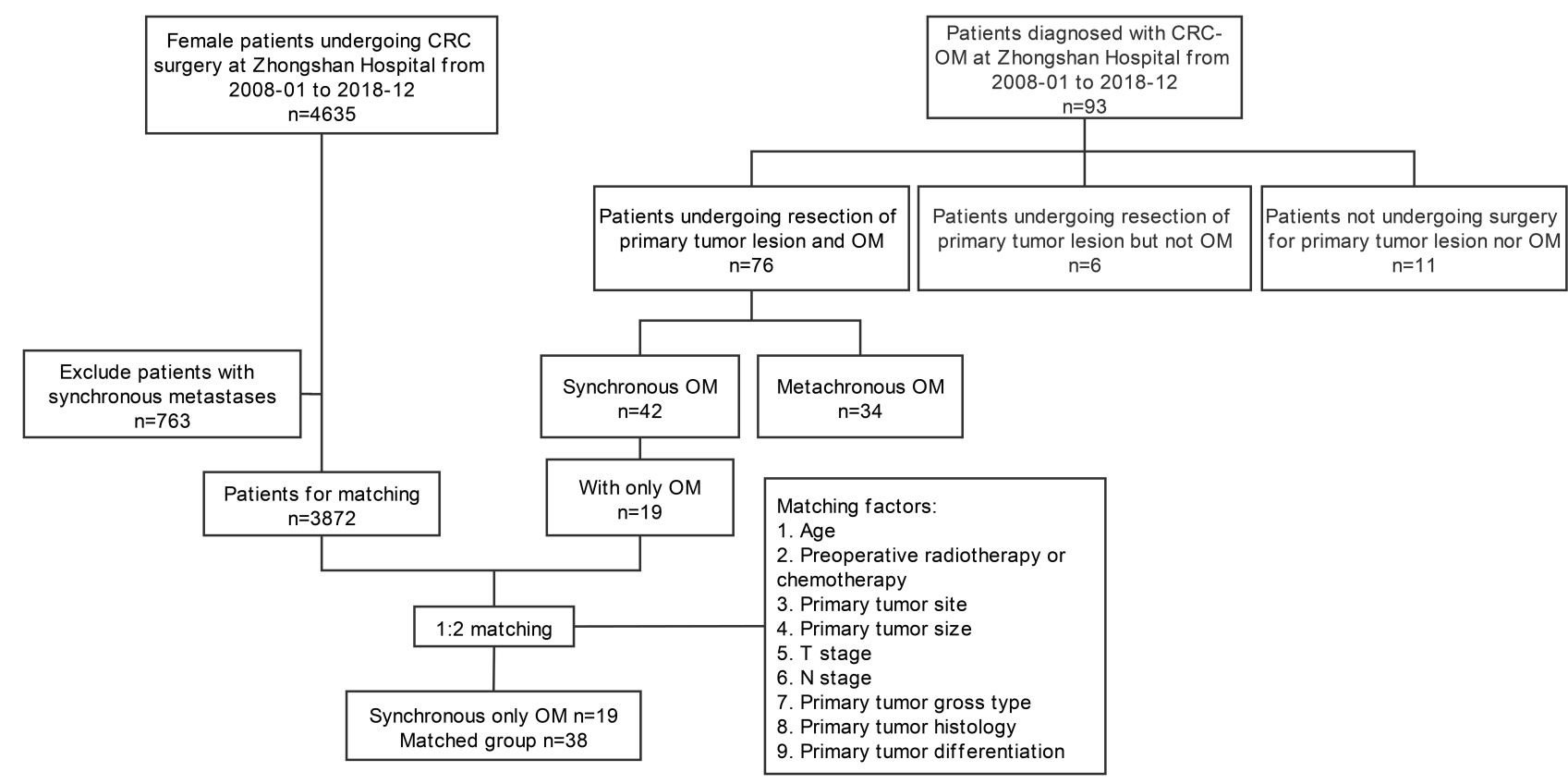

Figure I Flow chart of the matching of synchronous ovary-only metastasis patients and CRC patients with no metastases. 
be significant $(\mathrm{P}<0.05)$ by univariate analysis were further analyzed using a multivariate Cox proportional hazards regression model. Significant factors by Cox's analysis are expressed as hazard ratios (HR values) with 95\% confidence intervals (CIs). When the differences in clinicopathologic features between patients with synchronous and metachronous metastases and between patients with synchronous ovarian metastases and without metastases patients were analyzed, continuous variables were compared using Student's $t$-test or the Mann-Whitney $U$-test. Categorical variables were compared with Pearson's chisquare test. SPSS, version 25.0 (SPSS, Chicago, IL, USA), was used for analysis. GraphPad Prism, version 7.00 (GraphPad, San Diego, California, USA), was employed to draw the curves. All statistical tests were two-sided, and $\mathrm{p}$ values $<0.05$ were considered statistically significant.

\section{Results}

\section{Patient Characteristics}

Ninety-three patients with CRC-OM were enrolled in this study. Synchronous metastases were detected in 54 cases and metachronous metastases in 39 cases. Eleven patients did not receive surgery for either primary tumor lesions or ovarian metastases, 6 patients did not receive resection for ovarian metastases but did for primary tumor sites, and 76 patients underwent surgical resection of primary CRC and ovarian metastases. Among patients who underwent primary and ovarian metastases surgery, 42 were synchronous metastasis patients and 34 were metachronous metastasis patients. The median follow-up time was 17 months (range: 0-95). The mean age at diagnosis of CRC was 50.07 years (range: 26-78, SD: 12.82). The mean age at diagnosis of ovarian metastases was 50.66 years (range: 26-78, SD: 12.90). A total of $59.1 \%(n=55)$ of patients were premenopausal. Nearly half of the primary tumors $(n=43)$ originated from the left colon. The percentages of patients with synchronous metastases and metachronous metastases were 58.1\% $(n=54)$ and $41.9 \%(n=39)$, respectively. The median interval of metachronous metastases was 12 months (range: 3-43). More than half of the patients $(n=56)$ had both ovarian metastases and other metastases. Eleven patients received preoperative chemotherapy. Eighty-six (92.5\%) patients received different adjuvant chemotherapy regimens after the operation (Table 1). As analyzed by the Kaplan-Meier method, the median OS of CRC-OM patients was 26 months (Figure 2A), while the median OS times of patients with ovary-only metastases and those with ovarian metastases
Table I Baseline Characteristics of All Patients with CRC-OM

\begin{tabular}{|c|c|}
\hline Variables & \\
\hline Age at diagnosis of colorectal cancer, years $( \pm S D)$ & $50.07( \pm 12.82)$ \\
\hline$\leq 50$ & $55(59.1 \%)$ \\
\hline$>50$ & $38(40.9 \%)$ \\
\hline Age at diagnosis of ovarian metastases, years $( \pm S D)$ & $50.66( \pm 12.90)$ \\
\hline$\leq 50$ & $49(52.7 \%)$ \\
\hline$>50$ & $44(47.3 \%)$ \\
\hline \multicolumn{2}{|l|}{$\begin{array}{l}\text { Menopausal status at diagnosis of ovarian } \\
\text { metastases }\end{array}$} \\
\hline No & 55 (59.1\%) \\
\hline Yes & 38 (40.9\%) \\
\hline \multicolumn{2}{|l|}{ Primary tumor site } \\
\hline Right colon & $24(25.8 \%)$ \\
\hline Left colon & $43(46.2 \%)$ \\
\hline Rectum & $26(28.0 \%)$ \\
\hline \multicolumn{2}{|l|}{ Ovarian metastasis } \\
\hline Synchronous & $54(58.1 \%)$ \\
\hline Metachronous & 39 (4I.9\%) \\
\hline Internal time, months (quartile) & $12(8-18.5)$ \\
\hline \multicolumn{2}{|l|}{ Extent of metastatic disease } \\
\hline Ovary-only metastases & 37 (39.8\%) \\
\hline Combined with other metastases & $56(60.2 \%)$ \\
\hline Liver & $35(62.5 \%)$ \\
\hline Lung & $17(30.4 \%)$ \\
\hline Bone & $2(3.6 \%)$ \\
\hline Peritoneum & $23(41.1 \%)$ \\
\hline \multicolumn{2}{|l|}{ Surgery } \\
\hline No resection of ovarian metastases & $17(18.3 \%)$ \\
\hline Resection of ovarian metastases & $76(81.7 \%)$ \\
\hline \multicolumn{2}{|l|}{ Adjuvant chemotherapy } \\
\hline None & 7 (7.5\%) \\
\hline FOLFOX/FOLFIRI/CapeOx & 49 (52.7\%) \\
\hline FOLFOX/FOLFIRI/CapeOx+Bmab & $8(8.6 \%)$ \\
\hline FOLFOX/FOLFIRI+Cmab & 9 (9.7\%) \\
\hline 5-Fu/Cape & $6(6.4 \%)$ \\
\hline Unknown & 14 (I5.1\%) \\
\hline OS, months & 26 \\
\hline
\end{tabular}

Abbreviations: CRC-OM, colorectal cancer ovarian metastases; SD, standard deviation; OS, overall survival; FOLFOX, 5-FU + leucovorin + oxaliplatin; FOLFIRI, 5-FU + leucovorin + irinotecan; Cape, capecitabine; CapeOX, capecitabine + oxaliplatin, Bmab, bevacizumab; Cmab, cetuximab.

combined with other metastases patients were 49 months and 20 months, respectively (Figure $2 \mathrm{~B}$ and $\mathrm{C}$ ).

\section{Factors Affecting the Survival of Patients with CRC-OM}

Univariate analysis showed that patients with only ovarian metastases had a longer OS time (HR (95\% CI), 5.331 
A

No. at risk

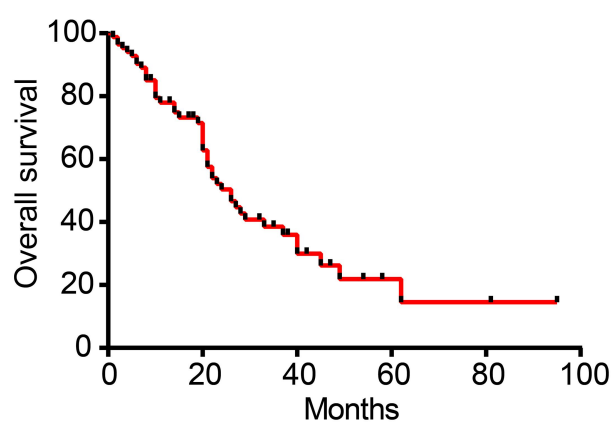

CRC-OM

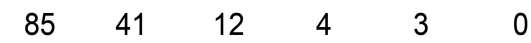

B

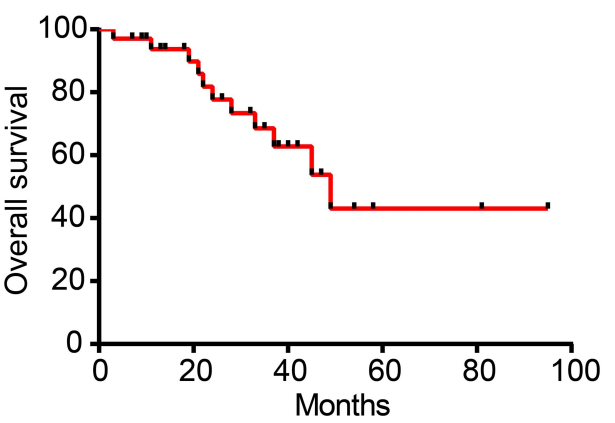

No. at risk

CRC-OM

24

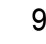

3

30

C

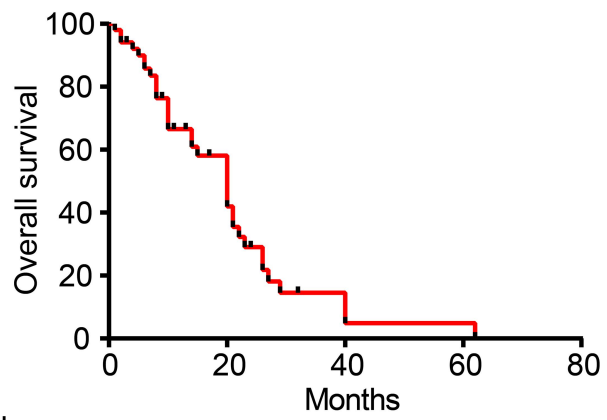

No. at risk

CRC-OM

$\begin{array}{llll}51 & 18 & 3 & 3\end{array}$

Figure 2 (A) OS of CRC-OM patients. (B) OS of CRC patients with ovary-only metastases. (C) OS of CRC-OM patients with other metastases.

(2.463-11.537), $\mathrm{p}<0.001$ ) (Figure 3A) than patients with other metastases. Resection of ovarian metastases was significantly associated with longer OS (HR $(95 \% \mathrm{CI})$, 4.864 (2.598-9.110), $\mathrm{p}<0.001)$ for CRC-OM patients (Figure 3B) and for patients with metastases in one or more organs in addition to the ovary (HR $(95 \% \mathrm{CI})$, 4.420 (1.566-12.48), $\mathrm{p}=0.005$ ) (Figure 3C). Additionally, age $<50$ years at diagnosis of $\mathrm{CRC}$ and ovarian metastasis
A

No. at risk

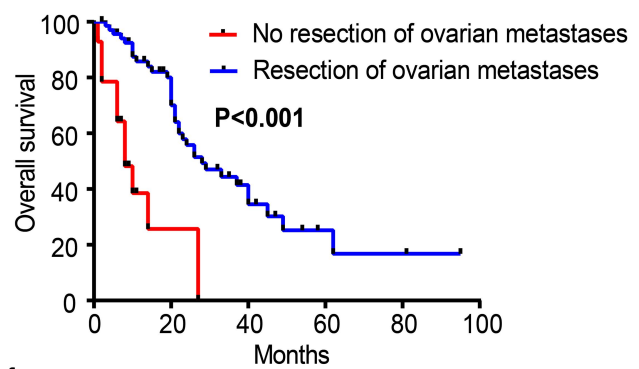

No resection of

ovarian metastases $14 \quad 3 \quad 0 \quad 00000$

Resection of

ovarian metastases $\begin{array}{llllll}71 & 40 & 12 & 4 & 3 & 0\end{array}$

B

No. at risk

Combined with other metastases

Ovary-only metastases

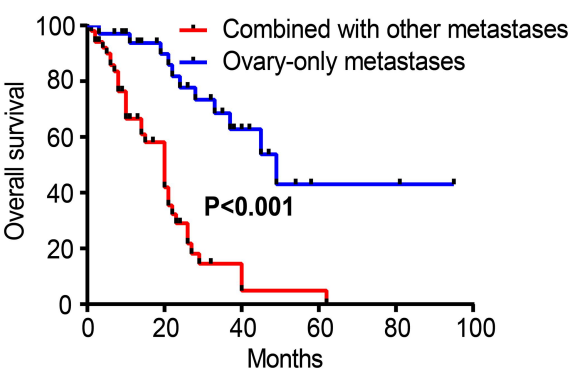

C

No. at risk

No resection of

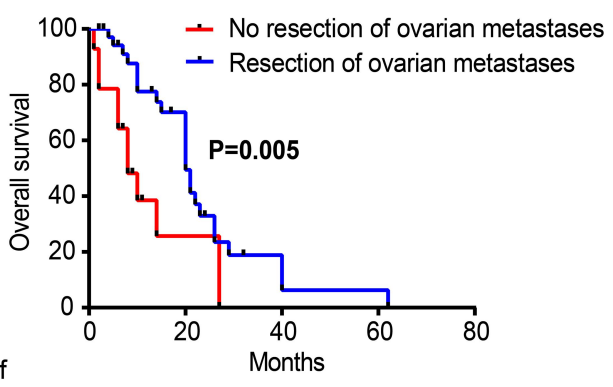

$\begin{array}{llllll}\text { ovarian metastases } & 14 & 3 & 0 & 0 & 0\end{array}$

Resection of

$\begin{array}{llllll}\text { ovarian metastases } & 37 & 17 & 3 & 3 & 0\end{array}$

Figure 3 (A) OS of patients with (blue curve) and without (red curve) ovarian metastasis resection. (B) OS of patients with ovary-only metastases (blue curve) and those with ovary combined with other metastases (red curve). (C) OS of patients with other metastases who underwent (blue curve) and did not undergo (red curve) ovarian metastasis resection.

may indicate a worse $\mathrm{OS}(\mathrm{p}=0.037, \mathrm{p}=0.027)$. In addition, there was no significant correlation between prognosis and menopausal status, primary tumor site, synchronous or metachronous metastases, postoperative chemotherapy or adjuvant chemotherapy. Multivariate analysis showed that patients with ovarian metastases alone had a longer OS time (HR (95\% CI), 3.633 (1.678-7.868), p=0.001). Moreover, longer OS (HR (95\% CI), 3.508 (1.503-8.190), $\mathrm{p}=0.002)$ was significantly associated with ovarian metastasis resection (Table 2). 


\section{Factors Affecting CRC-OM Surgery}

To explore the factors that affected the feasibility of metastasis resection, a comparison of the characteristics of patients with and without resection of ovarian metastases was carried out We found that the combination of ovarian metastases with other metastases was the only associated factor $(p<0.001)$. Other factors including age at diagnosis of $\mathrm{CRC}$ or ovarian metastases, menopausal status, primary tumor site, synchronous or metachronous ovarian metastases, and chemotherapy were not significantly related to conducting surgical treatments (Table 3). The results indicated that the assessment of the extent of metastases was important for determining surgical treatment.

\section{Comparison Between Synchronous and Metachronous Ovarian Metastases}

To explore the characteristics and prognosis of patients with synchronous or metachronous ovarian metastases, 54 patients with synchronous and 39 patients with metachronous metastases were enrolled in this study $(n=93)$, among whom 42 synchronous and 34 metachronous metastasis patients underwent metastasis resection. The

Table 2 Univariate and Multivariate Analyses of OS in All Patients with CRC-OM

\begin{tabular}{|c|c|c|c|c|}
\hline \multirow[t]{2}{*}{ Variables } & \multicolumn{2}{|c|}{ Univariate Analysis } & \multicolumn{2}{|c|}{ Multivariate Analysis } \\
\hline & HR (95\% Cl) & $P$ value & HR (95\% Cl) & $P$ value \\
\hline $\begin{array}{l}\text { Age at diagnosis of primary colorectal cancer, years }( \pm S D) \\
\quad \leq 50 \\
>50\end{array}$ & $\begin{array}{l}\text { I (reference) } \\
0.52(0.28-0.96)\end{array}$ & 0.037 & $1.07(0.23-4.98)$ & 0.934 \\
\hline $\begin{array}{l}\text { Age at diagnosis of ovarian metastases, years }( \pm \mathrm{SD}) \\
\leq 50 \\
>50\end{array}$ & $\begin{array}{l}\text { I (reference) } \\
0.51(0.28-0.93)\end{array}$ & 0.027 & $0.58(0.13-2.50)$ & 0.461 \\
\hline $\begin{array}{l}\text { Menopausal status at diagnosis of ovarian metastases } \\
\text { No } \\
\text { Yes }\end{array}$ & $\begin{array}{l}\text { I (reference) } \\
0.62(0.34-1.13)\end{array}$ & 0.12 & NA & NA \\
\hline $\begin{array}{l}\text { Primary tumour site } \\
\text { Right colon } \\
\text { Left colon } \\
\text { Rectum }\end{array}$ & $\begin{array}{l}\text { I (reference) } \\
1.70(0.78-3.74) \\
2.22(0.96-5.12)\end{array}$ & 0.174 & NA & NA \\
\hline $\begin{array}{l}\text { Ovarian metastasis } \\
\text { Synchronous } \\
\text { Metachronous }\end{array}$ & $\begin{array}{l}\text { I (reference) } \\
0.89(0.48-1.63)\end{array}$ & 0.694 & NA & NA \\
\hline $\begin{array}{l}\text { Extent of metastatic disease } \\
\text { Ovary-only metastases } \\
\text { Combined with other metastases }\end{array}$ & $\begin{array}{l}\text { I (reference) } \\
4.86(2.60-9.11)\end{array}$ & $<0.001$ & $3.63(1.68-7.87)$ & 0.001 \\
\hline $\begin{array}{l}\text { Surgery } \\
\text { Resection of ovarian metastases } \\
\text { No resection of ovarian metastases }\end{array}$ & $\begin{array}{l}\text { I (reference) } \\
5.33(2.46-\mid \text { I. } .54)\end{array}$ & $<0.001$ & $3.51(1.50-8.19)$ & 0.002 \\
\hline $\begin{array}{l}\text { Adjuvant chemotherapy } \\
\text { None } \\
\text { FOLFOX/FOLFIRI/CapeOx } \\
\text { FOLFOX/FOLFIRI/CapeOx+Bmab } \\
\text { FOLFOX/FOLFIRI+Cmab } \\
\text { 5-Fu/Cape }\end{array}$ & $\begin{array}{l}\text { I (reference) } \\
0.65(0.23-1.85) \\
1.33(0.28-6.26) \\
0.34(0.08-1.40) \\
0.33(0.06-1.81)\end{array}$ & $0.27 I$ & NA & NA \\
\hline
\end{tabular}

Note: A p-value in bold type means a significant difference $(p<0.05)$.

Abbreviations: CRC-OM, colorectal cancer ovarian metastases; SD, standard deviation; OS, overall survival; HR, hazard ratio; Cl, confidence interval; FOLFOX, 5-FU + leucovorin + oxaliplatin; FOLFIRI, 5-FU + leucovorin + irinotecan; Cape, capecitabine; CapeOX, capecitabine + oxaliplatin, Bmab, bevacizumab; Cmab, cetuximab. 
Table 3 Comparison of the Characteristics of Patients with and without Resection of Ovarian Metastases

\begin{tabular}{|c|c|c|c|}
\hline Variables & $\begin{array}{l}\text { No Resection of Ovarian } \\
\text { Metastases }\end{array}$ & $\begin{array}{l}\text { Resection of Ovarian } \\
\text { Metastases }\end{array}$ & $P$ value \\
\hline Age at diagnosis of colorectal cancer, years $( \pm S D)$ & $49.77( \pm 13.77)$ & $50.13( \pm 12.69)$ & 0.916 \\
\hline$\leq 50$ & II (64.7\%) & 44 (57.9\%) & 0.606 \\
\hline$>50$ & $6(35.3 \%)$ & $32(42.1 \%)$ & \\
\hline Age at diagnosis of ovarian metastases, years $( \pm S D)$ & $50.18( \pm 13.70)$ & $50.76( \pm \mid 2.81)$ & 0.867 \\
\hline$\leq 50$ & II (64.7\%) & $38(50.0 \%)$ & 0.272 \\
\hline$>50$ & $6(35.3 \%)$ & $38(50.0 \%)$ & \\
\hline $\begin{array}{l}\text { Menopausal status at diagnosis of ovarian } \\
\text { metastases }\end{array}$ & & & 0.606 \\
\hline No & II (64.7\%) & 44 (57.9\%) & \\
\hline Yes & $6(35.3 \%)$ & $32(42.1 \%)$ & \\
\hline Primary tumor site & & & 0.625 \\
\hline Right colon & $3(17.6 \%)$ & $21(27.6 \%)$ & \\
\hline Left colon & $8(47.1 \%)$ & $35(46.1 \%)$ & \\
\hline Rectum & $6(35.3 \%)$ & $20(26.3 \%)$ & \\
\hline Ovarian metastasis & & & 0.247 \\
\hline Synchronous metastases & $12(70.6 \%)$ & $42(55.3 \%)$ & \\
\hline Metachronous metastases & 5 (29.4\%) & $34(44.7 \%)$ & \\
\hline Extent of metastatic disease & & & $<0.001$ \\
\hline Ovary-only metastases & $0(0.0 \%)$ & $37(48.7 \%)$ & \\
\hline Combined with other metastases & $17(100.0 \%)$ & $39(51.3 \%)$ & \\
\hline Adjuvant chemotherapy & & & 0.673 \\
\hline None & I (5.9\%) & $6(7.9 \%)$ & \\
\hline FOLFOX/FOLFIRI/CapeOx & $9(52.9 \%)$ & $40(52.6 \%)$ & \\
\hline FOLFOX/FOLFIRI/CapeOx+Bmab & $2(11.8 \%)$ & $6(7.9 \%)$ & \\
\hline FOLFOX/FOLFIRI+Cmab & $3(17.6 \%)$ & $6(7.9 \%)$ & \\
\hline 5-Fu/Cape & $0(0.0 \%)$ & $6(7.9 \%)$ & \\
\hline Unknown & $2(11.8 \%)$ & $12(15.8 \%)$ & \\
\hline
\end{tabular}

Note: A p-value in bold type means a significant difference $(p<0.05)$.

Abbreviations: SD, standard deviation; FOLFOX, 5-FU + leucovorin + oxaliplatin; FOLFIRI, 5-FU + leucovorin + irinotecan; Cape, capecitabine; CapeOX, capecitabine + oxaliplatin, Bmab, bevacizumab; Cmab, cetuximab.

median interval between CRC surgery and detection of metachronous ovarian metastases was 12 months (range: 3-43 months). The majority ( $85.3 \%$ ) developed ovarian metastases 2 years after CRC surgery. The clinicopathological information of the synchronous and metachronous ovarian metastasis groups was compared. Features including age under 50 years $(\mathrm{p}=0.020)$ and premenopausal status $(\mathrm{p}=0.030)$ were found to be characteristic of synchronous metastasis cases (Table 4). Survival analysis showed no significant difference in OS between synchronous and metachronous ovarian metastasis cases (HR (95\% CI), 1.127 (0.614-2.09), $\mathrm{p}=0.689$ ) (Figure 4A). There was also no significant difference after resection of primary and ovarian metastases lesions (HR (95\% CI), $1.043(1.520-2.095), p=0.905)$ (Figure 4B).
CRC Ovary-Only Metastasis Patients Could Achieve Similar Survival Outcomes to Those of Patients Without Metastases After Surgery

To further clarify the benefits of surgery for CRC-OM patients after resection of primary and ovarian metastasis sites, for the first time, 38 patients without metastases who underwent CRC surgery were selected for a 1:2 match with only synchronous ovarian metastasis patients. After matching, there was no significant difference in those factors between the two groups $(\mathrm{p}>0.1)$ (Table 5). Survival analysis showed no significant difference after surgery between patients with only ovarian metastases and patients without any metastases, regardless of whether 
Table 4 Comparison of the Characteristics of Synchronous and Metachronous Ovarian Metastases Patients

\begin{tabular}{|c|c|c|c|}
\hline Variables & Synchronous Metastases & Metachronous Metastases & $P$ value \\
\hline $\begin{array}{l}\text { Age at diagnosis of colorectal cancer, years }( \pm S D) \\
\leq 50 \\
>50\end{array}$ & $\begin{array}{l}49.09( \pm 13.39) \\
34(63.0 \%) \\
20(37.0 \%)\end{array}$ & $\begin{array}{l}51.41( \pm 12.02) \\
21(53.8 \%) \\
18(36.2 \%)\end{array}$ & $\begin{array}{l}0.393 \\
0.377\end{array}$ \\
\hline $\begin{array}{l}\text { Age at diagnosis of ovarian metastases, years }( \pm S D) \\
\quad \leq 50 \\
>50\end{array}$ & $\begin{array}{l}49.09( \pm 13.39) \\
34(63.0 \%) \\
20(37.0 \%)\end{array}$ & $\begin{array}{l}52.82( \pm 12.03) \\
15(38.5 \%) \\
24(61.5 \%)\end{array}$ & $\begin{array}{l}0.171 \\
0.02\end{array}$ \\
\hline $\begin{array}{l}\text { Menopausal status at diagnosis of ovarian metastases } \\
\text { No } \\
\text { Yes }\end{array}$ & $\begin{array}{l}37 \text { (68.5\%) } \\
17(31.5 \%)\end{array}$ & $\begin{array}{l}2 \mid(53.8 \%) \\
\text { I8 (36.2\%) }\end{array}$ & 0.03 \\
\hline $\begin{array}{l}\text { Primary tumor site } \\
\text { Right colon } \\
\text { Left colon } \\
\text { Rectum }\end{array}$ & $\begin{array}{l}14(25.9 \%) \\
22(40.8 \%) \\
18(33.3 \%)\end{array}$ & $\begin{array}{l}10(25.6 \%) \\
21(53.8 \%) \\
8(20.6 \%)\end{array}$ & 0.377 \\
\hline $\begin{array}{l}\text { Extent of metastatic disease } \\
\text { Ovary-only metastases } \\
\text { Combined with other metastases }\end{array}$ & $\begin{array}{l}19(35.2 \%) \\
35(64.8 \%)\end{array}$ & $\begin{array}{l}18(36.2 \%) \\
21(53.8 \%)\end{array}$ & 0.286 \\
\hline $\begin{array}{l}\text { Surgery } \\
\text { No resection of ovarian metastases } \\
\text { Resection of ovarian metastases }\end{array}$ & $\begin{array}{l}12(22.2 \%) \\
42(77.8 \%)\end{array}$ & $\begin{array}{l}5(12.8 \%) \\
34(87.2 \%)\end{array}$ & 0.247 \\
\hline $\begin{array}{l}\text { Adjuvant chemotherapy } \\
\text { None } \\
\text { FOLFOX/FOLFIRI/CapeOx } \\
\text { FOLFOX/FOLFIRI/CapeOx+Bmab } \\
\text { FOLFOX/FOLFIRI+Cmab } \\
\text { 5-Fu/Cape } \\
\text { Unknown }\end{array}$ & $\begin{array}{l}4(7.4 \%) \\
30(55.6 \%) \\
6(11.1 \%) \\
7(13.0 \%) \\
1 \text { (1.9\%) } \\
6(11.1 \%)\end{array}$ & $\begin{array}{l}3(7.7 \%) \\
19(48.7 \%) \\
2(5.1 \%) \\
2(5.1 \%) \\
5(12.8 \%) \\
8(20.6 \%)\end{array}$ & 0.149 \\
\hline
\end{tabular}

Note: $A$ p-value in bold type means a significant difference $(p<0.05)$.

Abbreviations: SD, standard deviation; FOLFOX, 5-FU + leucovorin + oxaliplatin; FOLFIRI, 5-FU + leucovorin + irinotecan; Cape, capecitabine; CapeOX, capecitabine + oxaliplatin, Bmab, bevacizumab; Cmab, cetuximab.

DFS ( $\mathrm{p}=0.799, \mathrm{HR}(95 \% \mathrm{CI}), 1.154(0.382-3.483))$ or OS $(\mathrm{p}=0.848$, HR (95\% CI), $1.112(0.376-3.283))$ (Figure 5A and B) was analyzed.

In summary, the results indicated that after resection of primary and metastatic lesions, the DFS and OS of patients with only ovarian metastases were not different from those of patients without any metastases.

\section{Discussion}

CRC-OM is an important cause of death among female patients who are not sensitive to chemotherapy and have a poor prognosis. Six studies in the past 20 years showed that the median survival time of CMC-OM was 15-43.1 months. ${ }^{5,8-12}$ In this study, the median survival time of all patients was 29 months. CRC patients with only ovarian metastases had a better survival outcome, with a median OS of 49 months, while patients with other metastases had a worse prognosis, with a median OS of 20 months. Therefore, the combination with other metastases might be responsible for the poor prognosis of CRC-OM.

The median survival time of the patients with primary tumor and ovarian metastasis resection was 34 months. Multiple-factor analysis showed whether combined metastases in addition to ovary and ovary resection were vital factors affecting the prognosis of patients with CRC-OM. CRC-OM patients with other metastases who underwent removal of primary lesions and resection of ovarian metastases could also have an improved OS. All of the above findings suggest that surgical removal of the primary tumor and ovarian metastases can effectively improve the survival outcome. An increasing number of scholars have proposed that aggressive surgical treatment is an important therapeutic approach to ovarian metastases. Compared with simple systemic chemotherapy, it can significantly 


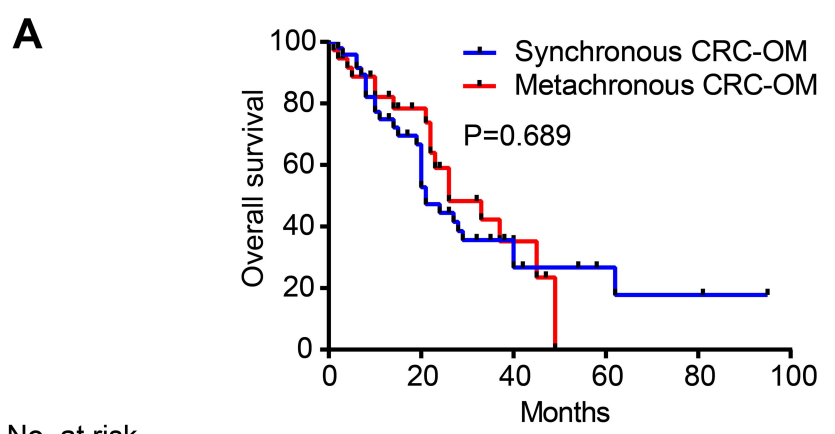

No. at risk

$\begin{array}{lcccccc}\begin{array}{l}\text { Synchronous ovarian } \\ \text { metastases }\end{array} & 48 & 24 & 8 & 4 & 3 & 0 \\ \begin{array}{l}\text { Metachronous ovarian } \\ \text { metastases }\end{array} & 37 & 18 & 4 & 0 & 0 & 0\end{array}$

\section{B}

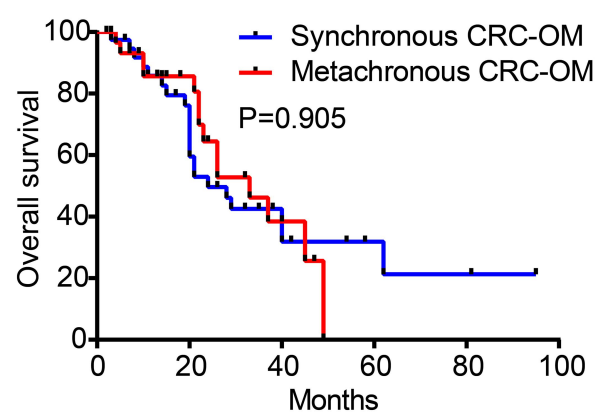

No. at risk

\begin{tabular}{|c|c|c|c|c|c|}
\hline $\begin{array}{l}\text { Synchronous ovarian } \\
\text { metastases }\end{array}$ & 39 & 23 & 8 & 4 & 3 \\
\hline $\begin{array}{l}\text { Metachronous ovarian } \\
\text { metastases }\end{array}$ & 32 & 18 & 4 & 0 & 0 \\
\hline
\end{tabular}

Figure 4 (A) OS of synchronous (blue curve) and metachronous (red curve) CRCOM patients. (B) OS of synchronous (blue curve) and metachronous (red curve) CRC-OM patients who had primary lesion and ovarian metastasis resection.

improve the survival time. ${ }^{5,9,12,13}$ Most studies also agree that the extent of tumor metastasis is an important factor affecting the prognosis of patients. ${ }^{14-17}$ Metastasis beyond the pelvic cavity, especially peritoneal metastasis, often indicates a poor prognosis. ${ }^{11,18}$ The mean age at diagnosis of CRC was 50.07 years (range: 26-78, SD: 12.82), which was much younger than CRC female patients without ovarian metastases $(n=4542$, median age: 62 , range: 19-92, $\mathrm{p}<0.001)$. In addition, we found that in CRC-OM patients, the proportion of premenopausal patients $(59.1 \%)$ was higher than that of menopausal patients (40.9\%). Mille et $\mathrm{al}^{8}$ found that $28 \%$ of premenopausal women with CRC may have ovarian metastases, while only $3.6 \%$ of menopausal women do. This may be related to the rich local blood supply of young women's ovaries. Whether it is related to the level of female hormones needs further research. In our study, most of the patients with ovarian metastases received adjuvant chemotherapy after operation. We also compared chemotherapy and different chemotherapy schemes, but no significant differences were found, which may be related to ovarian metastases being insensitive to chemotherapy compared with other metastases. The result was consistent with previous reports. Sekine et $\mathrm{al}^{5}$ found that only $23.5 \%$ of CRC-OM patients were sensitive to palliative chemotherapy. Goere et $\mathrm{al}^{6}$ provided the evidence that more than $80 \%$ of CRC-OM patients could not escape disease progression after treatment with preoperative chemotherapy. In conclusion, systemic chemotherapy alone may provide very limited improvement on the prognosis of patients. ${ }^{6}$ We also compared the characteristics of patients with and without resection of ovarian metastases and determined whether other metastases in addition to those of the ovary were important for the surgeon's evaluation of the feasibility of surgery.

Several single-center studies of more than 100 cases showed that the incidence rate of synchronous OM was $0-9 \%$ and that the incidence rate of metachronous $\mathrm{OM}$ was $0.9-7 \% .{ }^{14,19,20}$ We also compared the survival times of patients with synchronous ovarian metastases and to those of patients with metachronous ovarian metastases; there were no statistically significant differences. Some studies approved that synchronous or metachronous ovarian metastases were not the vital factor for the prognosis of CRC-OM patients. ${ }^{14}$ But some other studies thought the survival of synchronous metastases was much better. ${ }^{21} \mathrm{We}$ also found patients with synchronous ovarian metastases tended to be younger than 50 years and premenopausal, so young women with CRC need to be more alert to the possibility of ovarian metastases. Metachronous ovarian metastases usually occurred within 2 years after the CRC operation, which suggested that female patients should be aware of the possibility of metachronous ovarian metastases within 2 years after the CRC operation to facilitate early detection and treatment for a better prognosis. But Kim et al ${ }^{14}$ suggested that ( $82.8 \%$ ) patients had metachronous metastases within 3 years. Larger samples and prospective clinical researches are needed to further identify.

To further clarify the benefits of surgical resection of metastases, we matched and then analyzed the data of patients with only synchronous ovarian metastases and those with no metastases. Although the prognosis of patients with ovarian metastases is poor, we first found 
Table 5 A 1:2 Matched Analysis Using Without Metastasis Cases as Control from 3872 Colorectal Cancer Cases During 2008 to 2018

\begin{tabular}{|c|c|c|c|}
\hline \multirow[t]{2}{*}{ Covariates } & \multicolumn{3}{|l|}{ Matched Cohort } \\
\hline & Ovarian Metastases & Without Ovarian Metastases & $P$ value \\
\hline Age, years $( \pm S D)$ & $53.68 \pm 15.57$ & $49.32 \pm 15.06$ & 0.312 \\
\hline $\begin{array}{l}\text { Preoperative radiotherapy or chemotherapy } \\
\text { No } \\
\text { Yes }\end{array}$ & $\begin{array}{l}17(89.5 \%) \\
2(10.5 \%)\end{array}$ & $\begin{array}{l}36(94.7 \%) \\
2(5.3 \%)\end{array}$ & 0.463 \\
\hline $\begin{array}{l}\text { Primary tumor site } \\
\text { Right colon } \\
\text { Left colon } \\
\text { Rectum }\end{array}$ & $\begin{array}{l}6(31.6 \%) \\
5(26.3 \%) \\
8(42.1 \%)\end{array}$ & $\begin{array}{l}\text { II (28.9\%) } \\
7(18.4 \%) \\
20(52.6 \%)\end{array}$ & 0.708 \\
\hline Primary tumor size, $\mathrm{cm}( \pm \mathrm{SD})$ & $5.00(4.00-7.00)$ & $4.50(3.38-6.00)$ & 0.175 \\
\hline $\begin{array}{l}\text { Operation method } \\
\text { Laparotomy } \\
\text { Minimally invasive }\end{array}$ & $\begin{array}{l}13 \text { (68.4\%) } \\
6(31.6 \%)\end{array}$ & $\begin{array}{l}18(47.4 \%) \\
20(52.6 \%)\end{array}$ & 0.132 \\
\hline $\begin{array}{l}\text { T-stage of primary tumor } \\
2 \\
3 \\
4\end{array}$ & $\begin{array}{l}0(0.0 \%) \\
8(42.1 \%) \\
\text { II ( } 57.9 \%)\end{array}$ & $\begin{array}{l}0(0.0 \%) \\
15(39.5 \%) \\
23(60.5 \%)\end{array}$ & 0.849 \\
\hline $\begin{array}{c}\text { N-stage of primary tumor } \\
0 \\
1 \\
2\end{array}$ & $\begin{array}{l}3(15.8 \%) \\
5(26.3 \%) \\
\text { II }(57.9 \%)\end{array}$ & $\begin{array}{l}7(18.4 \%) \\
9(23.7 \%) \\
22(57.9 \%)\end{array}$ & 0.958 \\
\hline $\begin{array}{l}\text { Primary tumor gross type } \\
\text { Protruding } \\
\text { Ulcerative } \\
\text { Constrictive }\end{array}$ & $\begin{array}{l}6(31.6 \%) \\
12(63.1 \%) \\
I(5.3 \%)\end{array}$ & $\begin{array}{l}14(36.8 \%) \\
22(57.9 \%) \\
2(5.3 \%)\end{array}$ & 0.924 \\
\hline $\begin{array}{l}\text { Primary tumor histology } \\
\text { Adenocarcinoma } \\
\text { Mucinous } \\
\text { Signet ring cell type }\end{array}$ & $\begin{array}{l}14(73.7 \%) \\
4(21.1 \%) \\
I(5.2 \%)\end{array}$ & $\begin{array}{l}30(78.9 \%) \\
6(15.8 \%) \\
2(5.3 \%)\end{array}$ & 0.885 \\
\hline $\begin{array}{l}\text { Primary tumor differentiation } \\
\text { Moderately differentiated } \\
\text { Poorly differentiated }\end{array}$ & $\begin{array}{l}7(36.8 \%) \\
12(63.2 \%)\end{array}$ & $\begin{array}{l}10(26.3 \%) \\
28(73.7 \%)\end{array}$ & 0.413 \\
\hline
\end{tabular}

Abbreviations: SD, standard deviation; FOLFOX, 5-FU + leucovorin + oxaliplatin; FOLFIRI, 5-FU + leucovorin + irinotecan; Cape, capecitabine; CapeOX, capecitabine + oxaliplatin, Bmab, bevacizumab; Cmab, cetuximab.

no significant difference in DFS or OS after surgery. Therefore, we suggest that patients with synchronous ovarian metastases of CRC should undergo surgery for both primary and metastatic lesions to improve their prognosis. There is no previous study addressing the survival of patients with ovarian metastases and of patients without metastases after multiple-factor matching. Our results indicate the benefits and importance of surgical resection of ovarian metastases.
There are still some limitations of this study. Because of difficulties in data collection and the complexity of the clinical treatment of patients without surgery, this study failed to collect more clinical information of patients with ovarian metastases of CRC without surgery. Moreover, the sample size was relatively small for a retrospective singlecenter analysis. It is still necessary to further verify the conclusion by prospective multicenter and larger-sample clinical research. 
A

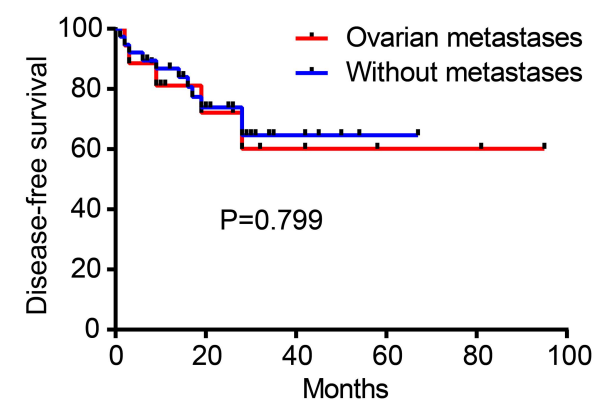

No. at risk

$\begin{array}{ccccccc}\text { Ovarian metastases } & 18 & 9 & 5 & 3 & 3 & 0 \\ \text { Without metastases } & 38 & 21 & 7 & 3 & 2 & 0\end{array}$

B

No. at risk

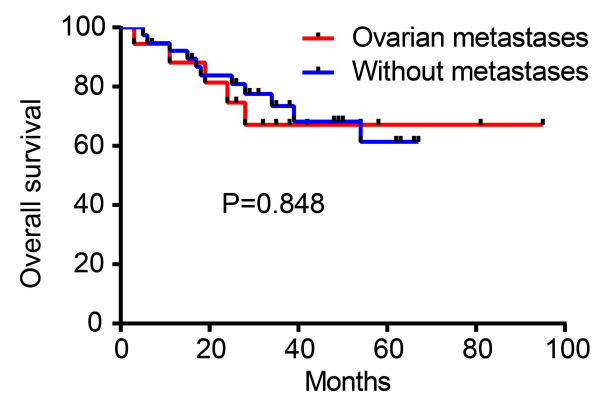

$\begin{array}{lcccccc}\text { Ovarian metastases } & 18 & 13 & 6 & 3 & 3 & 0 \\ \text { Without metastases } & 38 & 30 & 15 & 10 & 3 & 0\end{array}$

Figure 5 (A) DFS of patients with ovary-only metastases after primary and metastatic lesion resection (red curve) and DFS of patients without any metastases after primary lesion resection (blue curve). (B) OS of patients with ovary-only metastases after primary and metastatic lesion resection (red curve) and OS of patients without any metastases after primary lesion resection (blue curve).

\section{Conclusion}

CRC-OM patients could achieve longer survival times after primary and metastatic lesion surgery. There was no significant difference in OS after surgery between patients with only ovarian metastases and patients without metastases. There was no significant difference in the prognosis of patients with synchronous and those with metachronous ovarian metastases. Hence, our study suggests aggressive surgical treatment for patients with $\mathrm{CRC}-\mathrm{OM}$ to help achieve a better prognosis.

\section{Ethical Approval and Informed Consent}

The study was approved by the Ethics Committee of Zhongshan Hospital, Fudan University. All clinical investigations were conducted according to the principles expressed in the Declaration of Helsinki. Each subject provided their written informed consent.

\section{Acknowledgments}

Yuqiu Xu would like to thank Dr. Feng, Dr Xu and Dr. He for their careful guidance in this thesis.

\section{Author Contributions}

All authors made substantial contributions to conception and design, acquisition and analysis of data; took part in drafting and revising the article; agreed to submit to the current journal; gave final approval of the version to be published; and agree to be accountable for all aspects of the work.

\section{Disclosure}

The authors report no conflicts of interest in this work.

\section{References}

1. Bray F, Ferlay J, Soerjomataram I, Siegel RL, Torre LA, Jemal A. Global cancer statistics 2018: GLOBOCAN estimates of incidence and mortality worldwide for 36 cancers in 185 countries. CA Cancer J Clin. 2018;1-31. doi:10.3322/caac.21492

2. Zheng RS, Sun KX, Zhang SW, et al. Report of cancer epidemiology in China, 2015. Zhonghua Zhong Liu Za Zhi. 2019;41(1):19-28. doi:10.3760/cma.j.issn.0253-3766.2019.01.005

3. Wright JD, Powell MA, Mutch DG, et al. Synchronous ovarian metastases at the time of laparotomy for colon cancer. Gynecol Oncol. 2004;92(3):851-855. doi:10.1016/j.ygyno.2003.12.017

4. Grafner OL, Alm OA, Oscarson EA. Prophylactic oophorectomy in colorectal carcinoma. Obstet Gynecol Surv. 1983;146(233):226-228.

5. Sekine K, Hamaguchi T, Shoji H, et al. Retrospective analyses of systemic chemotherapy and cytoreductive surgery for patients with ovarian metastases from colorectal cancer: a single-center experience. Oncology. 2018;95(4):220-228. doi:10.1159/000489665

6. Goere D, Daveau C, Elias D, et al. The differential response to chemotherapy of ovarian metastases from colorectal carcinoma. Eur J Surg Oncol. 2008;34(12):1335-1339. doi:10.1016/j.ejso.2008.0 3.010

7. Ursem C, Zhou M, Paciorek A, et al. Clinicopathologic characteristics and impact of oophorectomy for ovarian metastases from colorectal cancer. Oncologist. 2020;25(7):564-571. doi:10.1634/ theoncologist.2019-0282

8. Mille BE, Pittman B, Wan JY, Fleming M. Colon cancer with metastasis to the ovary at time of initial diagnosis. Gynecol Oncol. 1997;66 (3):368-371. doi:10.1006/gyno.1997.4811

9. McCormick CC, Giuntoli RL 2nd, Gardner GJ, et al. The role of cytoreductive surgery for colon cancer metastatic to the ovary. Gynecol Oncol. 2007;105(3):791-795. doi:10.1016/j. ygyno.2007.02.025

10. Chung TS, Chang HJ, Jung KH, et al. Role of surgery in the treatment of ovarian metastases from colorectal cancer. J Surg Oncol. 2009;100(7):570-574. doi:10.1002/jso.21382

11. Fujiwara A, Noura S, Ohue M, et al. Significance of the resection of ovarian metastasis from colorectal cancers. J Surg Oncol. 2010;102 (6):582-587. doi:10.1002/jso.21675 
12. Ganesh K, Shah RH, Vakiani E, et al. Clinical and genetic determinants of ovarian metastases from colorectal cancer. Cancer. 2017;123 (7):1134-1143. doi:10.1002/cncr.30424

13. Erroi F, Scarpa M, Angriman I, et al. Ovarian metastasis from colorectal cancer: prognostic value of radical oophorectomy. J Surg Oncol. 2007;96(2):113-117. doi:10.1002/jso.20803

14. Kim DD, Park IJ, Kim HC, Yu CS, Kim JC. Ovarian metastases from colorectal cancer: a clinicopathological analysis of 103 patients. Colorectal Dis. 2009;11(1):32-38. doi:10.1111/j.1463-1318.2008.01543.x

15. Rayson D, Bouttel E, Whiston F, Stitt L. Outcome after ovarian or adnexal metastectomy in metastatic colorectal carcinoma. J Surg Oncol. 2000;75:186-192. doi:10.1002/1096-9098(200011)75:3<186:: AID-JSO6>3.0.CO;2-S

16. Lee SJ, Lee J, Lim HY, et al. Survival benefit from ovarian metastatectomy in colorectal cancer patients with ovarian metastasis: a retrospective analysis. Cancer Chemother Pharmacol. 2010;66 (2):229-235. doi:10.1007/s00280-009-1150-2
17. Xu KY, Gao H, Lian ZJ, Ding L, Li M, Gu J. Clinical analysis of Kruckenberg tumours in patients with colorectal cancer - a review of 57 cases. World J Surg Oncol. 2017;15(1):25. doi:10.1186/s12957016-1087-y

18. Tan KL, Tan WS, Lim JF, Eu KW. Krukenberg tumors of colorectal origin: a dismal outcome-experience of a tertiary center. Int $J$ Colorectal Dis. 2010;25(2):233-238. doi:10.1007/s00384-009-0796-x

19. Hanna NN, Cohen AM. Ovarian neoplasms in patients with colorectal cancer: understanding the role of prophylactic oophorectomy. Clin Colorectal Cancer. 2004;3(4):215-222. doi:10.3816/CCC.2004.n.002

20. Alberto C, Snchez R, Piniella F, et al. Management of non-hepatic metastatic disease in colorectal cancer. Surg Diagn Treat. 2014:191. doi:10.5772/57487

21. Huang PP, Weber TK, Mendoza C, Rodriguez-Bigas MA, Petrelli NJ. Long-term survival in patients with ovarian metastases from colorectal carcinoma. Ann Surg Oncol. 1998;5(8):695-698. doi:10.1007/bf02303479

\section{Publish your work in this journal}

Cancer Management and Research is an international, peer-reviewed open access journal focusing on cancer research and the optimal use of preventative and integrated treatment interventions to achieve improved outcomes, enhanced survival and quality of life for the cancer patient.
The manuscript management system is completely online and includes a very quick and fair peer-review system, which is all easy to use. Visit http://www.dovepress.com/testimonials.php to read real quotes from published authors. 